\title{
Successful endovascular embolisation of a jejunal artery aneurysm
}

Zhiwen Joseph $\underline{L O}^{1}$, MBBS, MRCS, Jeffrey J Leow ${ }^{1,2}$, MBBS, MPH, Ker-Kan $\underline{\operatorname{Tan}}^{3}$, MBBS, FRCS, Glenn Wei Leong $\underline{\operatorname{Tan}}{ }^{1}$, MBChB, FRCS

\begin{abstract}
Jejunal artery aneurysms are rare, with only six cases reported in the literature to date. Endovascular embolisation of the jejunal artery is rarely performed. Herein, we report the case of a 57-year-old man who successfully underwent endovascular embolisation for bleeding caecal diverticulosis, during which a 9-mm fusiform jejunal artery aneurysm was incidentally diagnosed. Subsequently, the jejunal aneurysm was successfully embolised using Vortex coils.
\end{abstract}

Keywords: aneurysm, embolisation, jejunal artery, visceral artery

\section{INTRODUCTION}

Endovascular embolisation of the jejunal artery is not a common procedure due to the rarity of its clinical indications. Coupled with the fact that jejunal arterial branches have one or few arcades, there is, theoretically, a risk for bowel ischaemia following embolisation. To date, there are only six case reports of jejunal artery aneurysms published in the literature, five of which underwent endovascular embolisation. ${ }^{(1-6)}$ We present a case of successful embolisation of a 9-mm jejunal artery aneurysm, which was found incidentally, and a brief review of the literature.

\section{CASE REPORT}

We present the case of a 57-year-old non-smoker with a significant past medical history of colon diverticulosis, which was first diagnosed in April 2009 after he presented with haematochezia. Colonoscopy performed then had revealed florid caecal, ascending hepatic flexure and sigmoid diverticulosis. He was readmitted in July 2013 with a two-day history of 14 episodes of haematochezia. It was similar to his previous 2009 presentation. The patient did not have any symptoms of intestinal obstruction or ischaemic bowel, nor did he report any constitutional or anaemic symptoms. He had no family history of inflammatory bowel disease.

On physical examination, the patient was alert, afebrile, normotensive (blood pressure: 113/64) and not tachycardic (heart rate: $89 \mathrm{bpm}$ ). His abdomen was soft and non-tender, with no sign of peritonitis. Digital rectal examination revealed fresh blood stains but no melaena or mass. Proctoscopy was negative for haemorrhoids and rectal ulcers. Full blood count revealed normocytic, normochromic anaemia, with haemoglobin level at $8.0 \mathrm{~g} / \mathrm{dL}$. Coagulation profile, liver function tests and cardiac enzymes were all normal. Plain chest and abdominal radiography did not reveal any bowel obstruction or viscus perforation. After resuscitation and transfusion with 3 units of packed red blood cells, his haemoglobin level improved to $9.4 \mathrm{~g} / \mathrm{dL}$.
Colonoscopy performed the next day after bowel preparation, demonstrated pan-colonic diverticulosis with altered blood staining the left colon. However, there was no evidence of any active bleed. Intubation of the terminal ileum did not suggest bleeding proximally from the small intestine.

Although haemodynamically stable, the patient had three further episodes of haematochezia, with haemoglobin level dropping to $7.5 \mathrm{~g} / \mathrm{dL}$. Computed tomography (CT) mesenteric angiography revealed bleeding colonic diverticulosis, with active contrast extravasations at the caecum and proximal ascending colon. The patient then underwent successful endovascular embolisation of the bleeding caecal vasa recta with two 3-mm Vortex coils and one 2-mm Helical coil.

During the procedure, there was an incidental finding of a 9-mm fusiform jejunal artery aneurysm (Fig. 1). Management options of surveillance versus endovascular embolisation were discussed, and given the context of the bleeding diverticular disease, the patient was keen to proceed with embolisation to prevent future jejunal artery aneurysmal complications. The following day, he underwent endovascular embolisation. Intraoperatively, the aneurysm was identified with a selective superior mesentery artery angiogram. A C1 catheter was advanced into the jejunal branch harbouring the aneurysm and a Progreat microcatheter was then inserted coaxially into the jejunal branch and advanced beyond the aneurysm. Initial embolisation of the distal artery with a 4-mm Vortex coil failed, as the coil spontaneously migrated proximally into the sac. Subsequently, a 4-mm and a 3-mm coil were successfully deployed into the distal artery and a 6-mm Vortex coil was deployed within the sac. The proximal artery was successfully embolised with another 4-mm Vortex coil. Complete occlusion of the jejunal branch was then demonstrated, with no filling of the aneurysmal sac. Distal bowel was well perfused via a jejunal collateral network (Fig. 2).

The patient had an uneventful post-procedure recovery and was discharged four days later with no further bleeding episodes

${ }^{1}$ Department of General Surgery, Tan Tock Seng Hospital, Singapore, ${ }^{2}$ Center for Surgery and Public Health, Brigham and Women's Hospital, Boston, MA, USA, ${ }^{3}$ Division of Colorectal Surgery, University Surgical Cluster, National University Health System, Singapore

Correspondence: Dr Zhiwen Joseph Lo, Department of General Surgery, Tan Tock Seng Hospital, 11 Jalan Tan Tock Seng, Singapore 308433. zhiwen@gmail.com 
Table I. Published case reports of jejunal aneurysms or pseudoaneurysms.

\begin{tabular}{|c|c|c|c|c|}
\hline Author & Background and possible cause & Presentation & Diagnostic modality & Treatment \\
\hline $\begin{array}{l}\text { Shimohira } \\
\text { et } \mathrm{al}^{(1)}\end{array}$ & $\begin{array}{l}\text { History of coronary artery } \\
\text { bypass using gastroepiploic } \\
\text { arteries }\end{array}$ & $\begin{array}{l}\text { Incidental during 3D-CT } \\
\text { performed to evaluate } \\
\text { conditions of graft }\end{array}$ & 3D-CT & $\begin{array}{l}\text { Embolisation using } \\
\text { interlocking detachable } \\
\text { coils }\end{array}$ \\
\hline $\begin{array}{l}\text { Bavunoglu } \\
\text { et } \mathrm{al}^{(2)}\end{array}$ & Intestinal tuberculosis & $\begin{array}{l}\text { Massive acute upper Gl } \\
\text { bleed (> } 2 \mathrm{~L} \text { in } 20 \mathrm{~min} \text { ) }\end{array}$ & CT angiography & $\begin{array}{l}\text { Embolisation with } \\
\text { histoacryl glue }\end{array}$ \\
\hline $\begin{array}{l}\text { Sonnenschein } \\
\text { et } \mathrm{al}^{(3)}\end{array}$ & Jejunal arterovenous fistula & $\begin{array}{l}\text { Upper abdominal pain and } \\
\text { vomiting for suspected } \\
\text { acute pancreatitis }\end{array}$ & $\begin{array}{l}\text { MR imaging and CT } \\
\text { angiography }\end{array}$ & $\begin{array}{l}\text { Embolisation with five } \\
5-7 \mathrm{~mm} \text { micro-coils }\end{array}$ \\
\hline Vibert et $\mathrm{al}^{(4)}$ & Unknown & Pancreaticoduodenectomy & $\begin{array}{l}\text { Found incidentally during } \\
\text { pancreaticoduodenectomy }\end{array}$ & Embolisation \\
\hline Røkke et $\mathrm{al}^{(5)}$ & Unknown & Unknown & CT angiography & Embolisation \\
\hline $\begin{array}{l}\text { Weinstock } \\
\text { et } \mathrm{al}^{(6)}\end{array}$ & $\begin{array}{l}\text { Small bowel obstruction caused } \\
\text { by extrinsic compression of } \\
\text { duodenum by a mesenteric } \\
\text { haematoma }\end{array}$ & $\begin{array}{l}\text { Sudden onset of severe, } \\
\text { sharp periumbilical pain } \\
\text { with syncopal episodes }\end{array}$ & CT angiography & $\begin{array}{l}\text { Spontaneous resolution } \\
\text { after evacuation of } \\
\text { organising haematoma } \\
\text { during laparotomy }\end{array}$ \\
\hline
\end{tabular}

CT: computed tomography; GI: gastrointestinal; MR: magnetic resonance

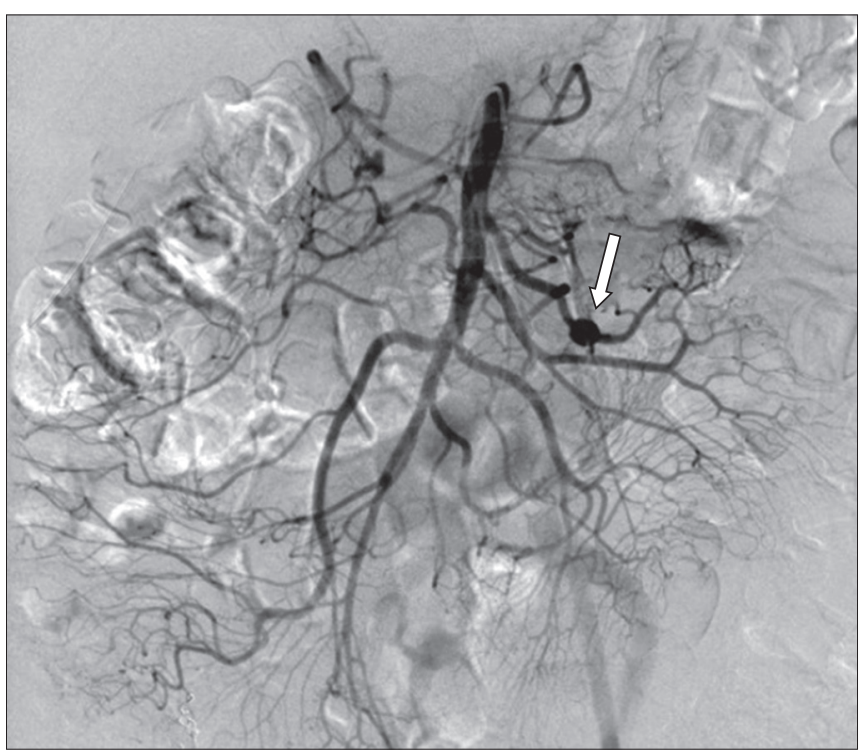

Fig. 1 Pre-embolisation CT mesenteric angiogram shows a 9-mm fusiform jejunal artery aneurysm (arrow).

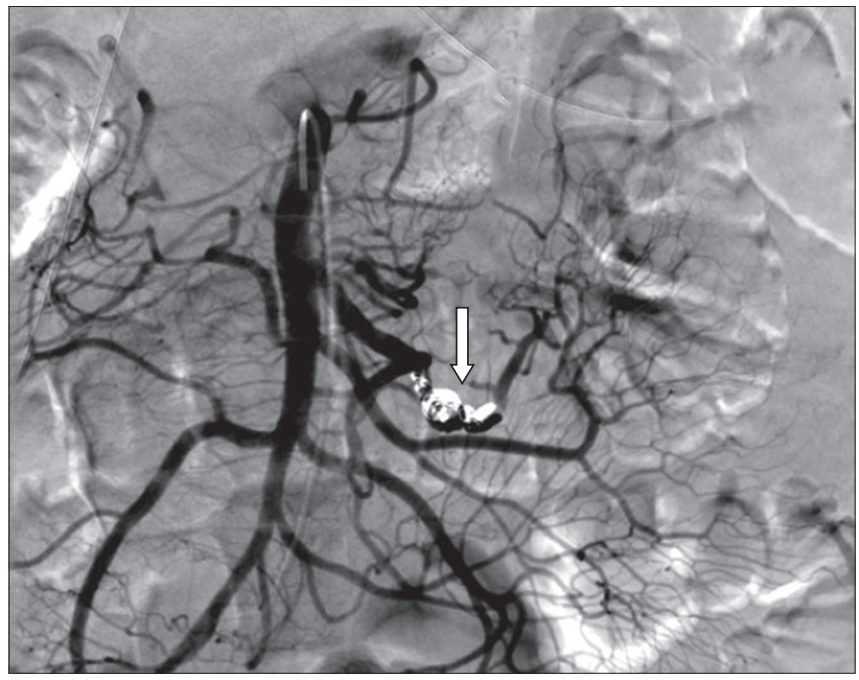

Fig. 2 Post-embolisation CT mesenteric angiogram shows complete occlusion of the jejunal branch, with no filling of the aneurysmal sac (arrow). Distal bowel was well perfused via a jejunal collateral network. or ischaemic complications. At review one month after discharge, the patient was well, and had no significant complaints and normal haemoglobin levels.

\section{DISCUSSION}

Jejunal artery aneurysms are rarely seen. There are only six such cases reported in the literature (Table I). ${ }^{(1-6)}$ Of the 18 case series of splanchnic artery aneurysms in the literature, only two out of a total of 561 patients were reported to have jejunal artery aneurysms. ${ }^{(7-10)}$ Jejunal artery aneurysms are usually diagnosed incidentally during CT radiography performed for another indication, ${ }^{(1-3,5,6)}$ and rarely, they may also be diagnosed during an operative procedure such as a pancreaticoduodenectomy. ${ }^{(4)}$ Any splanchnic artery aneurysm has significant clinical implications due to the possibility of causing rupture, bleeding and even occlusion, thus causing ischaemic bowel. All these are surgical emergencies and often associated with significant morbidity and mortality, especially if misdiagnosed during the initial presentation.

Traditionally, treatment of splanchnic artery aneurysms has been open surgical intervention due to their late presentation of aneurysmal ruptures. ${ }^{(7-9)}$ However, with the widespread use of CT angiography, there is increased detection of asymptomatic splanchnic artery aneurysms, in which treatment by angioembolisation has been shown to be effective as a first-line treatment with few complications and low recurrence rates. ${ }^{(2,5,7-8,11-15)}$ First described in 1974, angiographic diagnosis and treatment of gastrointestinal haemorrhage has since progressed significantly with advances in microcatheter technology, digital fluoroscopy and increased experience of interventional radiologists. Numerous reports have documented its safety and high rates of success of over $90 \%{ }^{(11)}$ However, these successes have mainly been limited to larger vessels supplying the colon. ${ }^{(11-13)}$ Treatment outcomes of embolisation of small bowel vessels are currently unclear, although our literature review documented success in all five attempted endovascular embolisation within six case reports (Table I). Nevertheless, there are associated risks of ischaemic or infarction events, rebleeding or recurrence. ${ }^{(11-13)}$ 
In conclusion, the growing literature documenting successful embolisation of jejunal artery with low incidences of bowel ischaemia and recurrence, coupled with the increasing expertise of intervention radiology and vascular surgery, suggests that endovascular intervention for aneurysms of the jejunal artery is gaining credence as a safe treatment for jejunal artery aneurysms.

\section{REFERENCES}

1. Shimohira M, Ogino H, Kitase M, Takeuchi M, Shibamoto Y. Embolization for asymptomatic aneurysms of the first jejunal artery. Vasa 2006; 35:198-200.

2. Bavunoglu I, Ayan F, Karabicak I, et al. Selective jejunal artery pseudoaneurysm embolization in a patient with massive gastrointestinal bleeding due to intestinal tuberculosis. J Emerg Med 2006; 31:391-4.

3. Sonnenschein MJ, Anderson SE, Lourens S, Triller J. A rare case of jejunal arterovenous fistula: treatment with superselective catheter embolization with a tracker-18 catheter and microcoils. Cardiovasc Intervent Radiol 2004; 27:671-4.

4. Vibert E, Kobeiter H, Malassagne B, Watrin T, Fagniez PL. [Rupture of a jejunal artery pseudo- aneurysm after a cephalic duodenopancreatectomy]. Ann Chir 2003; 128:626-9. French.

5. Røkke O, Søndenaa K, Amundsen SR, Bjerke Larssen T, Jensen D. Successful management of eleven splanchnic artery aneurysms. Eur J Surg 1997; 163:411-7.

6. Weinstock LB, Wu JS, Malden ES, et al. Small bowel obstruction resulting from mesenteric hematoma caused by spontaneous rupture of a jejunal branch artery. Gastrointest Endosc 1999; 49:537-40.

7. Grotemeyer D, Duran M, Park EJ, et al. Visceral artery aneurysms--followup of 23 patients with 31 aneurysms after surgical or interventional therapy. Langenbecks Arch Surg 2009; 394:1093-100.

8. Ikeda O, Tamura Y, Nakasone Y, Iryou Y, Yamashita Y. Nonoperative management of unruptured visceral artery aneurysms: treatment by transcatheter coil embolization. J Vasc Surg 2008; 47:1212-9.

9. Chen F, Wu Z. [Rupture of splanchnic artery aneurysms (a report of 19 cases)]. Zhonghua Xin Xue Guan Bing Za Zhi 1990; 18:26-7, 61. Chinese.

10 Miller MT, Comerota AJ, Disalle R, Kaufman A, Pigott JP. Endoluminal embolization and revascularization for complicated mesenteric pseudoaneurysms: a report of two cases and a literature review. J Vasc Surg 2007; 45:381-6.

11. Tan KK, Wong D, Sim R. Superselective embolization for lower gastrointestinal hemorrhage: an institutional review over 7 years. World J Surg 2008; 32:2707-15.

12. Gordon RL, Ahl KL, Kerlan RK, et al. Selective arterial embolization for the control of lower gastrointestinal bleeding. Am J Surg 1997; 174:24-8.

13. Silver A, Bendick P, Wasvary H. Safety and efficacy of superselective angioembolization in control of lower gastrointestinal hemorrhage. Am J Surg 2005; 189:361-3.

14. Bleichrodt RP, Smulders TA, Schreuder F, Tinbergen W, Müller WF. Aneurysms of the jejunal artery. J Cardiovasc Surg (Torino) 1984; 25:376-7.

15. Muscari F, Barret A, Chaufour X, et al. [Management of visceral artery aneurysms. Retrospective study of 23 cases]. Ann Chir 2002; 127:281-8. French. 